\title{
The Role of Typical Angina with Risk Factors in Predicting Stenosis
}

\author{
Aang Kunaifi \\ Faculty of Nursing Universitas Airlangga \\ Surabaya, Indonesia \\ aang.kunaifi-2015@fkp.unair.ac.id
}

\author{
Nursalam \\ Faculty of Nursing Universitas Airlangga \\ Surabaya, Indonesia
}

\author{
Mochamad Yusuf \\ Faculty of Nursing Universitas Airlangga \\ Surabaya, Indonesia
}

\begin{abstract}
One method for early detection of coronary stenosis that is Diagnostic Coronary Angiography (DCA). Diagnostic Coronary Angiography is a minimally invasive procedure using a diagnostic catheter and guide wire with the help of contrast. Catheterization in clients with complaints of chest pain are not all found stenosis (narrowing) of coronary arteries significantly; even some clients show the results of DCA without stenosis. Total client sampled 159 people, who do DCA catheterization with stenosis $\geq 70 \%$ (coronary artery disease) in March 2015 to the month of March 2017 at Universitas Airlangga Hospital (RS Unair) Surabaya, East Java, Indonesia. The findings were then each analyzed risk factors contained in the client retrospectively. The results were obtained by using stepwise logistic regression. The patients who met the criteria, 25 (15.72\%) had atypical chest pain, and $134(84.27 \%)$ had typical chest pain. Significant predictors of coronary artery disease (CAD) $\geq 70 \%$, by correlating risk factors with the type of chest pain (atypical chest pain and typical chest pain), included body mass index (BMI) and history of diabetes mellitus (DM) (all $p<0.05)$. Patients of CAD with excess BMI will have a typical chest pain risk of $\mathbf{1 . 1 6}$ probably compared with patients with lower BMI. Patients of CAD with thinner BMI are atypical chest pain. Patients with a history of DM will have atypical chest pain of 0.32 probably compared to patients who have no history of DM. Patients with CAD who did not have a history of DM are at risk of having typical chest pain. The variation in chest pain can be explained by both variables of $9.6 \%$. Accurate prediction of chest pain to the incidence of stenosis $\geq 70 \%$ through BMI and history of diabetes mellitus of $\mathbf{8 4 . 3 \%}$. Body mass index (BMI) and history of diabetes mellitus have a significant correlation to the incidence of chest pain in client with a degree of stenosis $\geq 70 \%$.

Keywords: CAD, predicting, coronary, stenosis
\end{abstract}

\section{INTRODUCTION}

Chest pain felt by someone whom has a risk factor for coronary artery disease (CAD) to be a signal disturbances in the organs, especially the coronary artery system [1]. Early detection of chest pain both typical chest pain or atypical chest pain can provide information on the condition of coronary arteries immediately [2]. Atypical chest pain with dyspnea can be the presenting symptom of CAD and was found to be present in $26 \%$ of patients. In another study, among $8.4 \%$ of the patients who presented without chest pain, nearly half of them had dyspnea only. Chest pain or other complaints have a poor prognosis [3]. Other studies suggest that there are several factors that cause CAD, 56\% hypertension, $45 \%$ hypercholesterolemia, $13 \%$ diabetes mellitus, $34 \%$ smokers, $21 \%$ obesity and $45 \%$ have a family history with Coronary Artery Disease (CAD) and who do not have risk factors An average of $2.6 \%$ [4]. The presence of chest pain complaints associated with risk factors is possible to predict the presence of stenosis $\geq 70 \%$.

\section{Methods}

This study was done in Universitas Airlangga Hospital, Surabaya, East Java, Indonesia. The study population was all patients with complaints of typical chest pain and atypical chest pain who visited Universitas Airlangga hospital in March 2015 until March 2017. The population in this study amount to 444 people.

For this study, patients were included if they have $\geq 70 \%$ stenosis based on catheterization, and complaints of typical or atypical chest pain. We excluded patients with Acute Coronary Syndromes (ACS), patients with Old Myocardial Infarction (OMI), patients with myocardial bridging, patients with DCA catheterization for preparation of coronary artery bypass graft surgery (CABG), and patients with incomplete medical records. The number of sample found in this research are 159 patients. This amount consists of 25 patients experience atypical chest pain, and 134 patients have typical chest pain. It will be analyzed the risk factors of this finding retrospectively.

The variables of this study are consist of dependent and independent variables. Dependent variable is chest pain type. Independent variables are age, gender, BMI, history of Diabetes Mellitus, history of hypertension, history of dyslipidemia, history of stroke, family history of CAD, and peripheral disease and history of smoking. 
Univariate analysis was used to describe the nature of each variable. The results were obtained by using stepwise logistic regression to determine the relationship among dependent and independent variables. Variables contained in this study was made into categorical and ratio scale.

\section{RESULTS}

The sample in this study as many as 159 people. Risk factors and complaints of chest pain (chest pain) experienced by clients into research data. The data were analyzed using candidate selection of independent variable with $\mathrm{p} \leq 0,250$, then tested again using logistic regression analysis test. The purpose of this study is to analyze some risk factors for the cause of stenosis found in clients with complaints typical chest pain and atypical chest pain.

Table 1 Client Characteristics Based on Risk Factors Against Chest Pain Type

\begin{tabular}{|c|c|c|c|}
\hline Characteristics & $\begin{array}{l}\text { Atypical } \\
\text { Chest } \\
\text { Pain } \\
(n=25)\end{array}$ & $\begin{array}{c}\text { Typical } \\
\text { Chest Pain } \\
(n=134)\end{array}$ & $\begin{array}{c}\text { P Value } \\
(p \leq \\
0,250)\end{array}$ \\
\hline Gender & & & 0.520 \\
\hline Female [n(\%)] & $8(32 \%)$ & $52(38.8 \%)$ & \\
\hline Male $[\mathrm{n}(\%)]$ & $17(68 \%)$ & $82(61.2 \%)$ & \\
\hline $\begin{array}{r}\text { Age (y) [median } \\
\text { (percentile 25, } \\
\text { percentile 75)] }\end{array}$ & $\begin{array}{l}58 \quad(49, \\
66)\end{array}$ & $\begin{array}{l}59 \\
66.75)\end{array}$ & 0.615 \\
\hline $\begin{array}{c}\text { Body Mass Index } \\
\text { (BMI) }\left(\mathrm{kg} / \mathrm{m}^{2}\right) \\
{[\text { median }} \\
\text { (percentile 25, } \\
\text { percentile } 75)]\end{array}$ & $\begin{array}{l}24 \\
(22.54, \\
26.87)\end{array}$ & $\begin{array}{l}25.52 \\
(23.11 \\
28.09)\end{array}$ & 0.092 \\
\hline $\begin{array}{c}\text { History of DM } \\
{[\mathrm{n}(\%)]}\end{array}$ & $16(64 \%)$ & $59(44 \%)$ & 0.071 \\
\hline $\begin{array}{l}\text { History of } \\
\text { Hypertension } \\
{[\mathrm{n}(\%)]}\end{array}$ & $18(72 \%)$ & 107 (79.9\%) & 0.382 \\
\hline $\begin{array}{c}\text { History of } \\
\text { Dyslipidemia } \\
{[\mathrm{n}(\%)]}\end{array}$ & $17(68 \%)$ & $82(61.2 \%)$ & 0.520 \\
\hline $\begin{array}{l}\text { History of Stroke } \\
{[\mathrm{n}(\%)]}\end{array}$ & $3(12 \%)$ & $9(6.7 \%)$ & 0.365 \\
\hline $\begin{array}{c}\text { Family history of } \\
\text { CAD [n(\%)] }\end{array}$ & $0(0 \%)$ & $3(2.2 \%)$ & 0.999 \\
\hline $\begin{array}{c}\text { History of } \\
\text { Peripheral } \\
\text { Vascular } \\
\text { Disease }[\mathrm{n}(\%)] \\
\end{array}$ & $0(0 \%)$ & $0(0 \%)$ & - \\
\hline $\begin{array}{l}\text { History of Smoke } \\
{[\mathrm{n}(\%)]}\end{array}$ & $8(32 \%)$ & 47 (35.1\%) & 0.767 \\
\hline
\end{tabular}

Selection of candidate independent variables obtained that the BMI and history of diabetes mellitus has a value of $\mathrm{p} \leq 0.250$, so the two variables are passed in the logistic regression analysis stage.
Table 1.2 Significant Client Risk Factors Significantly with Type of Chest Pain

Variables in the Equation

\begin{tabular}{|c|c|c|c|c|c|c|c|c|c|}
\hline & \multirow[t]{2}{*}{ B } & \multirow[t]{2}{*}{ S.E. } & \multirow[t]{2}{*}{$\begin{array}{c}\text { Wal } \\
\text { d }\end{array}$} & \multirow[t]{2}{*}{$\begin{array}{l}d \\
f\end{array}$} & \multirow[t]{2}{*}{ Sig. } & \multirow[t]{2}{*}{$\begin{array}{c}\operatorname{Exp}( \\
\text { B) }\end{array}$} & \multicolumn{2}{|c|}{$\begin{array}{l}\text { 95\% C.I.for } \\
\text { EXP(B) }\end{array}$} \\
\hline & & & & & & & & $\begin{array}{c}\text { Lowe } \\
r\end{array}$ & $\begin{array}{l}\text { Upp } \\
\text { er }\end{array}$ \\
\hline \multirow{3}{*}{$\begin{array}{c}\text { Step } \\
1^{\mathrm{a}}\end{array}$} & IMT & .153 & .071 & $\begin{array}{r}4.72 \\
9\end{array}$ & 1 & $\begin{array}{r}.03 \\
0\end{array}$ & 1.166 & 1.015 & $\begin{array}{r}1.33 \\
9\end{array}$ \\
\hline & $\mathrm{DM}$ & $\begin{array}{r}1.13 \\
4\end{array}$ & .483 & $\begin{array}{r}5.50 \\
8\end{array}$ & 1 & $\begin{array}{r}.01 \\
9\end{array}$ & .322 & .125 & .830 \\
\hline & $\begin{array}{c}\text { Consta } \\
n t\end{array}$ & -.434 & $\begin{array}{r}1.68 \\
5\end{array}$ & .066 & 1 & $\begin{array}{r}.79 \\
7\end{array}$ & .648 & & \\
\hline
\end{tabular}

a. Variable(s) entered on step 1: IMT, DM.

Variable of BMI and history of diabetes mellitus have pvalue $<0.05$ that both of these variables significantly related to the emergence of chest pain complaints on clients with degrees of stenosis $\geq 70 \%$. The variation in chest pain can be explained by both variables of $9.6 \%$. Accurate prediction of chest pain to the incidence of stenosis $\geq 70 \%$ through BMI and history of diabetes mellitus of $84.3 \%$.

Table 2 explains that the higher the body mass index (BMI) a person then the person with stenosis $\geq 70 \%$ experience typical chest pain. A person with a lower body mass index, will feel atypical chest pain. Patients with stenosis $\geq 70 \%$ with a history of DM is predicted to feel atypical chest pain, while stenosis $\geq 70 \%$ without history of DM more likely to experience typical chest pain.

\section{DISCUSSION}

Our main findings: the number of CAD patients more men than women is $62.2 \%$ and $37.7 \%$. These findings are in line with other research results that is $49 \%$ of men and $32 \%$ of women have a lifetime risk of developing CHD after 40 years of age [5]. But variable of sex does not determine the type of perceived chest pain.

This study stated that there is a relationship between BMI and the incidence of typical chest pain in patients with coronary stenosis. There is an opinion that mortality rates are higher in people with lower BMI in non-cardiac cases [6]. We agree with him because a lower BMI (thin) allows a person to have atypical chest pain. This condition makes the person ignore the complaints experienced so late handling.

Type and level of chest pain symptoms are affected by increasing age, high BMI and history of DM. Because on these factors there is the incidence of neuropathy [7]. We do not agree with that, because the higher a person's BMI the person becomes more alert because of the typical chest pain. For ages, some people can still distinguish the type of chest pain that is felt. Our DM history agrees because someone with DM tends to feel atypical chest pain. 
Variation of chest pain can be explained by both variables that is $9,6 \%$. This condition is possible there are risk factors outside this research variables such as race, and so on.

\section{CONCLUSION AND RECOMMENDATION}

Based on the findings of this study, it can be concluded that the occurrence of atypical chest pain makes a harmful phenomenon if not done to the public education. But with these predictors, it is possible for those with chest pain to be more alert by linking the risk factors present to them. Risk factors that can be a clear predictor when associated with typical chest pain and atypical chest pain to know there is a stenosis of BMI and history of DM.

\section{References}

[1] G. K. Hansson, "Inflammation, atherosclerosis, and coronary artery disease,” N. Engl. J. Med., vol. 352, no. 16, pp. 1685-1695, 2005.

[2] C. P. C. P. P. Writing et al., "National Heart Attack Alert Program position paper: chest pain centers and programs for the evaluation of acute cardiac ischemia," Ann. Emerg. Med., vol. 35, no. 5, pp. 462-
471, 2000.

[3] A. El-Menyar et al., “Atypical presentation of acute coronary syndrome: a significant independent predictor of in-hospital mortality,” J. Cardiol., vol. 57, no. 2, pp. 165-171, 2011.

[4] R. Nicoll et al., "The coronary calcium score is a more accurate predictor of signi fi cant coronary stenosis than conventional risk factors in symptomatic

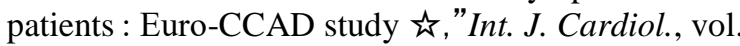
207, pp. 13-19, 2016.

[5] J. W. Beckstead and K. D. Stamp, "Understanding how nurse practitioners estimate patients' risk for coronary heart disease: a judgment analysis,” J. Adv. Nurs., vol. 60, no. 4, pp. 436-446, 2007.

[6] A. Ariza-solé et al., "Body mass index and acute coronary syndromes : Paradox or confusion?," 2015.

[7] A. E. Mbchb and M. Zubaid, “Atypical presentation of acute coronary syndrome : A significant independent predictor of in-hospital for the Gulf Registry of Acute Coronary Events ( Gulf RACE ) Investigators,” $J$. Cardiol., vol. 57, no. 2, pp. 165-171, 2011. 